\title{
The Development of the Virtual Notebook, a Wiki-Based Ready Reference Technology
}

Traditionally, library professionals have used a variety of ready reference technologies to assist in providing reference and user services. Technologies such as card files, vertical files, and reference notebooks are frequent components of library service desks. Ready reference technologies serve many purposes, most notably, helping staff to answer frequently asked questions and facilitating the sharing of information between library staff. This paper traces the development of the Virtual Notebook, a wiki-based ready reference technology, at Purdue University. The tool is placed within the historical context of ready reference technologies within the library profession and at Purdue. The authors present preliminary results from the implementation of the Virtual Notebook and discuss the tool's future. The manuscript is an outgrowth of a presentation at the 2008 Brick and Click Symposium at Northwest Missouri State University.

n 1897, Eleanor B. Woodruff, a librarian at the Pratt Institute Free Library, wrote in Library Journal of the repetitive nature of reference questions. She informed readers that "certain questions come around with the regularity of the seasons." With this and the effort sometimes devoted to answering a question in mind, Woodruff advocated librarians record ques- tions, answers, and sources on "spoiled catalog cards." Additionally, she urged librarians to take notes from their readings, record factoids, and paste clippings from the local newspaper on cards. She insisted that once assigned subject headings and arranged alphabetically, these old cards would become an essential reference resource. Locally developed reference technologies such as Woodruff's card file have long been used by librarians to answer questions in conjunction with commercially printed resources. Robert Slater made similar remarks in 2006, stating that at almost every reference desk one "can find an amalgamation of vertical files, Rolodexes, notebooks, desk blotter scribbles, post it notes, word processor documents, and webpages that together, represent the need-to-know information." ${ }^{3}$ Although reference technologies have evolved significantly since the time of "spoiled catalog cards," locally created resources continue to assist in answering patron's questions quickly and accurately.

Reference librarians frequently utilize reference technologies, whether books, vertical files, three-ring binders, card files, or electronic equivalents, as their first line of defense in answering questions. These resources contain information specific to a library and

\section{Matthew M. Bejune and Sara E. Morris}

Matthew M. Bejune is Coordinator of Library Reference and Instruction, Quinsigamond Community College, Worcester, Massachusetts. Bejune previously worked as the Digital Reference Services Coordinator at Purdue University Libraries. Sara E. Morris is Associate Librarian for American History, University of Kansas, Lawrence, Kansas. Morris previously worked as a Digital Reference Graduate Assistant at Purdue University Libraries. Submitted for review August 4, 2009; accepted for publication September 23, 2009.

Reference \& User Services Quarterly, vol. 50 , no. 1 , pp. $27-34$

(c) 2010 American Library Association. All rights reserved.

Permission granted to reproduce for nonprofit, educational use. 
its community, along with current information, frequently asked questions (FAQ), and answers to questions that librarians deem difficult. As new modes of reference have emerged, these resources have adapted. Tracing the history of reference tools places the development of Purdue University's Virtual Notebook in a historical narrative of ready reference technologies that is more evolutionary than revolutionary.

\section{DEFINITION OF TERMS}

Ready reference technologies are tools used to assist in the provision of reference and user services. They capture and record data, and in the process help them to proliferate so that they are more easily accessible. Common examples include notebooks, card files, vertical files, and their electronic equivalents. Library staff are crucial to the success of reference and user services and in many cases serve as repositories of data, information, and knowledge. Yet, in this context, staff members themselves are not considered ready reference technologies. First and foremost, library staff are people, not things or technologies. Second, the data, information, and knowledge stored within each library staff member is not easily accessible. Ready reference technologies make this tacit information explicit.

\section{THE EVOLUTION OF REFERENCE RESOURCES}

Reference librarians communicate with each other to better serve patrons. Whether notifying colleagues about classroom assignments or recently asked questions, librarians participate in knowledge management. Borrowed from the corporate world, knowledge management describes the methods an organization employs to share information. Early literature stressed the role of special librarians and their possession of skills to effectively assist this corporate activity. ${ }^{4}$ Townley addressed the role of the academic library in knowledge management in 2001. Townley defined knowledge management as "the set of processes that create and share knowledge across an organization." $\mathrm{He}$ lamented that while libraries assisted in the sharing and preservation of knowledge within their larger institutions, they failed to heed their own advice as a smaller entity within the larger organization.

On the most basic level, knowledge can be classified as either tacit or explicit. ${ }^{6}$ Tacit knowledge is what people know intuitively or have learned over time because of job specializationindividuals often view such information as unimportant. This perception of insignificance often results in tacit knowledge going unshared. Explicit knowledge has been shared either verbally or in writing. Printed documents like rules, regulations, and procedures are examples of explicit knowledge. Distributing information on scratch paper or in an e-mail transforms it from tacit to explicit.

How librarians share information with each other at the reference desk has received relatively little attention in the research literature. Presumably, the ubiquity of ready reference tools has led the research community to take them for granted and treat them as unworthy of studies concerning how many libraries have Rolodexes or how frequently reference desk staff consult their desk's three-ring binder. ${ }^{7}$ Instead, the majority of resources mentioning card files, vertical files, reference desk notebooks, or message clipboards are manuals and descriptions of local resources.

\section{TRADITIONAL REFERENCE DESK RESOURCES}

A common component of reference desks in the predigital age was a notebook or a binder where staff left messages for each other or copies of important information. In his column, "Pencils Never Crash," Bell wrote that his colleagues at his first professional position encouraged him not to just contribute to the shared notebook but to maintain his own. Bell's personal reference manual quickly became his most important reference source, and he filled the binder beyond capacity. Bell equated the librarian's relationship with this long-standing reference necessity to that of Peanuts character Linus's security blanket. ${ }^{8}$

The need for more permanent storage space than a notebook led to locally produced card files. The importance of this tool is evident in the textbook The Effective Reference Librarian. The authors gave detailed directions about when and how to create an entry, warning that "unsystematic storing of notes and file cards can keep a would-be reference librarian unproductively busy." Other librarians gave practical examples of how to use a card file as a complement to commercially produced products. ${ }^{10}$

Another supplementary tool, the vertical or pamphlet file, provided a method to organize larger pieces of printed information. Virginia Fairfax, a librarian at Carnation Milk Production Company, observed in 1921 that in the quickly changing world, books often arrived at the library out of date. To solve this problem she supplemented Carnation's book collection with a filing cabinet of current information. ${ }^{11} \mathrm{H}$.W. Wilson's inaugural issue of the Vertical File Index in 1932 demonstrated 
the widespread importance and adoption of the tool. This serial described pamphlets and ephemeral material, their price, and how libraries could obtain desired pieces. ${ }^{12}$ In 1954, Ireland advocated such resources as a solution for dated monographs and to supplement small serials collections. ${ }^{13}$

The importance of the vertical file resulted in various attempts to improve awareness through electronic access. In 1980, the Graduate School of Library and Information Science at UCLA attempted to automate the Undergraduate Libraries' information files, but failed because of insufficient technology. An attempt six years later succeeded. ${ }^{14}$ In 1989, the Spencer S. Eccles Health Sciences Library at the University of Utah added records for their vertical file to the online catalog using Medical Subject Headings. As a result, use of the files increased significantly. ${ }^{15}$ However, in the same year, Abbot declared, "The vertical file is the Rodney Dangerfield of our academic library's reference collection. It gets no respect."16 This bothered Abbot because he believed it to be the perfect resource for undergraduates.

\section{CHANGING RESOURCES FOR NEW FORMS OF REFERENCE}

The introduction of the telephone to library reference services led librarians to rethink how they provided their services. Libraries with high call volumes established specific desks to handle phone inquiries. Separated from resources at the desk, libraries built reference collection materials specifically for these areas. ${ }^{17}$ Some telephone collections were kept on a circular bookshelf that spun around for quick access. Without an official name, these reference technologies have been called wheels, lazy Susans, and information carousels. ${ }^{18}$

As chat and e-mail reference services emerged, librarians further reconceptualized resources needed to facilitate reference desk transactions. They debated where to physically staff chat and e-mail services: at the main reference desk or somewhere away from the public? A secondary problem became proximity to traditional reference resources. Did one need easy access to ready reference materials or the larger print reference collection? Such debates subsided as commercially produced resources became available electronically and information on the Internet grew. ${ }^{19}$

Electronic resources often did not address the need for locally produced information. Sauers offered bookmarks as a way to access locally important websites, but he warned that their association with a specific computer and browser made this an imperfect solution. Instead, Sauers suggested creating webpages that librarians could use anywhere. ${ }^{20}$ Another solution for digital reference services was canned or scripted messages. Normore and Rumbaugh equated this tool to the "card and Rolodex files traditionally kept to assist with either frequently-asked or hard-to-answer questions." ${ }^{\text {1 }}$ Others worried that these answers came across as impersonal, and therefore detracted from the personal nature of digital reference. ${ }^{22}$ Another option, FAQ pages were accessible to everyone at anytime. Joe Janes advocated for the creation of Frequently Asked Reference Question pages that addressed policy and technical questions. Recognizing the potential in already existing reference tools, Janes recommended turning to the card file to write the first iteration. ${ }^{23}$

\section{MODERNIZING THE REFERENCE LIBRARIAN'S TOOLBOX}

As libraries embraced computers and the Internet, librarians looked to technology to create better access to localized reference tools. Grainger Engineering Library at the University of Illinois at Urbana-Champaign created the database-driven Reference Assistant in the late 1990s. ${ }^{24}$ San Diego State and Oakland University also adopted database models. ${ }^{25}$ Bell offered a number of possible solutions using modern tools: digitize printed resources and post them to a website; use a bookmarking service such as Delicious, which does not tie access to a browser or a computer; or use a flash stick so librarians can carry the information with them. ${ }^{26}$ In "Time to Lose the Sticky and Try a Wiki" Bell outlined the problems of sticky notes as a method to communicate at the desk. He stressed their faults: the eventual loss of stickiness, the risk that someone cleaning the desk would remove a note before everyone read it, and, of course, the problem of illegible handwriting. As a replacement, he advocated reference departments look to wikis, a "nearly tailor-made solution for reference department communication." ${ }^{27}$ Wikis offer many advantages: they are free, require little technical knowledge, include notification features, and allow open access and the possibility for collaboration. ${ }^{28}$

The advantages Bell cited have resulted in many libraries using wikis for their internal resources. The University of Houston Music Library initially only planned to convert their policy and procedure manual to a wiki. However, this technology's usefulness resulted in the addition of other materials to the resource, taking it beyond just being a manual. The library's wiki became 
an important method for library staff, including students, to communicate. Through the wiki, staff kept gate-count statistics and even logged problems with the photocopier. ${ }^{29}$ The University of Texas at Austin initially created a wiki to provide staff unable to attend meetings with a way to keep up with important information. As the success of this initial use of this new technology became evident, staff decided to add information from the "Assistance Guide," a document containing answers to frequently asked questions. As a result, public services staff, no matter their location, could easily find and search for institutional information. ${ }^{30}$ Similarly, at Miami University the libraries implemented a wiki to share information with staff from multiple locations. Within a year of its implementation, the wiki completely replaced messages on e-mail lists or notes at the desk. ${ }^{31}$

\section{BUILDING THE VIRTUAL NOTEBOOK}

Another example of a ready reference tool is the Virtual Notebook developed by the authors when they were employed at Purdue. The Purdue University Libraries include eleven subject-oriented libraries, the Hicks Undergraduate Library, and the Virginia Kelly Karnes Archives and Special Collections Research Center. The Libraries offer 2.8 million printed volumes and electronic books, 40,000 electronic and print journals, more than 400 electronic databases, 3.1 million microforms, and federal government publications and patents received on a depository basis. The Libraries operating budget is around $\$ 25$ million, and they employ approximately 200 staff -73 faculty and professional staff, and 119 support staff.

Purdue University is a public land grant institution founded in 1869 located in West Lafayette, Indiana. It is a research-intensive university with a Carnegie Classification of Comprehensive Doctoral with Medical/Veterinary. The school has emphases within science, technology, engineering, and business. Enrollment is typically around forty thousand students per year.

Over the years a variety of ready reference technologies have been employed within the Libraries. The Undergraduate Library, perennially one of the busiest reference service points within the Purdue University Libraries, implemented a number of ready reference technologies including notebooks, clipboards, printouts, card files, and vertical files. ${ }^{32}$ Prior to the adoption of the Internet, the Reference Notebook contained a variety of print resources selected to facilitate answering reference questions. As more and more information became available electronically, the Reference
Notebook evolved and became a collection of print sources unavailable online or printouts of electronic sources better utilized in print. In conjunction with this notebook was another notebook for staff members to leave messages to one another. Over time this led to the creation of the Reference Clipboard, a collection of printouts of procedural and policy based e-mails and sticky notes from staff. In addition to the Reference Notebook there was a binder with ready reference information for use by staff and library patrons when the library reference desk was closed. This resource contained a listing of library hours, maps, and general information about the Libraries. In the recent past-perhaps ten years ago- the Undergraduate Library utilized a card file of three by five inch index cards. Cards contained information and sources for frequently asked topics. Similarly, there also was a vertical file, occupying about six linear feet, consisting of pamphlets, handouts, printouts, and clippings about Purdue, the community, the state of Indiana, and the United States. It also contained information about hot topics and travel. In 2009 the vertical file was heavily weeded for the first time in years.

\section{LAUNCH OF ASK A LIBRARIAN}

In March 2003, the Libraries launched Ask a Librarian (www.lib.purdue.edu/askalib), a chat and e-mail reference service powered by OCLC's QuestionPoint software. Ask a Librarian is was the first chat service at Purdue. It consolidates disparate e-mail addresses for each of the libraries into one centralized e-mail service. Ask a Librarian chat offers real-time assistance forty-eight hours per week. Ask a Librarian e-mail is available 24/7 with a promised turnaround time of one to two business days. In a typical month during the academic year the service receives between three hundred and five hundred questions, split roughly equally between chat and e-mail. Each year the service receives between twenty-five hundred and three thousand questions representing between 5 to 7 percent of reference traffic throughout the Purdue University Libraries.

During the first year the Ask a Librarian service was offered, it became clear that staff members needed additional assistance when chatting and e-mailing. At the time, nearly fifty staff from across the Libraries manned Ask a Librarian. For the first time, staff members who were accustomed to providing and customizing services geared toward constituents in their physical locations had to answer questions submitted by patrons of all subjects and developmental levels. While e-mail questions could be referred to staff members 
offline, chat questions needed to be answered at the point of need. As a result, adopting the Ask a Librarian service necessitated the creation of a support mechanism to aid staff working in unfamiliar areas. What follows is a breakdown of the ready reference technologies developed to address this scenario.

\section{Method 1: Chat and E-mail Scripts}

QuestionPoint, like most digital reference software applications, offers the ability to create scripts or canned messages. Scripts work on the premise that it is easier to paste precoordinated responses into chat or e-mail transcripts than to re-create the process of searching and typing each time a question arrives. QuestionPoint provides two types of scripts_-"My Scripts," personal scripts associated with individual QuestionPoint logins, and "Institution Scripts," which are shared across all logins. Staff members created their own My Scripts as part of their digital reference training. Institution Scripts were created by the digital reference services coordinator on behalf of all staff.

Scripts proved helpful in answering chat and e-mail questions when they were used by library staff. However, some staff did not use scripts because they found it difficult to view the contents of scripted messages in the midst of answering questions. This is a characteristic of the QuestionPoint interface. In QuestionPoint's defense, scripts are easier to view and edit offline. Other staff did not use the scripts because they found it easier and more natural to type messages in real time. Another barrier to using scripts was a system limitation within QuestionPoint permitting only twenty Institution Scripts. On one hand, a limitation in the number of scripts made it easier to view, manage, and use existing scripts. On the other, it stifled the authoring of scripted content to address new questions that had come in.

Given these obstacles, the digital reference services coordinator made changes to the Institution Scripts. Scripts that were procedural-those that helped staff work through the process of answering chat and e-mail questions-were retained. Scripts that were content-rich-those addressing frequently asked questions such as locating dissertations and theses, interlibrary loan, locating full-text journals, selecting databases, etc.-were removed. This move created additional space for procedural scripts within QuestionPoint and opened the door for the creation of a new ready reference resource to assist in the provision of all user services, not just chat and e-mail reference.

\section{Method 2: Reference FAQ 1.0}

The content-bearing scripts removed from QuestionPoint became the initial corpus of the first Reference FAQ created in early 2005. Additional content came from information sources-tacit and explicit-throughout the Libraries. The first Reference FAQ page was a flat text file similar to many early FAQ pages. It was largely a browseable resource, though it could be searched using a Web browser's find feature. The FAQ was far from elegant, and it had some usability issues, but it filled an immediate need. In addition to supporting all forms of reference and user services, it made tacit knowledge explicit in a way that was more publicly accessible to library staff and patrons alike. After the Reference FAQ was created and its utility for supporting all modes of reference became apparent, its ownership was transferred from the digital reference services coordinator to the reference services team, a group responsible for overseeing reference issues across the Libraries.

\section{Method 3: Reference FAQ 2.0}

Further development of the Reference FAQ began after the reference services team took ownership. At that time, staff members from the Engineering Library asked the Libraries Information Technology Department to create a tool to support the management, creation, and publication of FAQs. This led to the construction of the FAQ Search Engine, or as it was frequently called, the FAQ Engine. When the reference services team learned about the FAQ Engine, it was co-opted to produce the Purdue Libraries Reference FAQ 2.0 (http:// gemini.lib.purdue.edu/rstfaq/index.cfm) in the Spring of 2005. The FAQ Engine is built upon a database as opposed to a flat text file. Questions may be categorized and assigned keywords to help facilitate recall of FAQ content when searching the FAQ Engine. The FAQ Engine presents content within tables formatted to match the Web design of the Libraries website. Questions can be expanded or collapsed individually or collectively. The display is decidedly Google-like. In contrast to the long list of FAQs in version 1.0, version 2.0 began with a search box and the open-ended question, "How do I . . ?" Knowing that some users might want to view the entire list of FAQs, as in the previous version, a link was made to a page that permitted users to view and browse the entire collection of FAQs. Access to version 2.0 of the FAQ was enhanced by moving it from the Help section of the website to the Self-Service section of the Ask a Librarian page (www.lib.purdue.edu/askalib).

Version 2.0 was a significant improvement 
over version 1.0, though there continued to be challenges. First, maintaining current, accurate content was an issue. When the FAQ Engine was launched the content was up to date, but over time it slowly became outdated. Keeping any FAQ current requires constant and vigilant maintenance. Although version 2.0 was easier to update than version 1.0, staff needed to have logins and be trained to use the FAQ Engine. A second challenge related to ownership. When the Reference FAQ was transferred to the reference services team from the digital reference services coordinator it was loosely controlled. This was so that the development of the FAQ would be open to all Libraries staff and not stifled by a select few with narrow perspectives of reference services. Unfortunately, the result of this decision was that instead of the FAQ being owned by all Libraries staff, it was owned and updated by few.

\section{Method 4: The Virtual Notebook}

In May 2007, the Libraries launched an enterprise wiki powered by Atlassian Confluence software as a replacement to the preexisting Libraries intranet. Libraries councils, committees, and teams created wiki spaces to store and share documents in support of collaborative group work. The wiki permitted asynchronous and synchronous work as well as remote and place-based work. At this time, the researchers began to investigate if the wiki could be used to support the next version of the FAQ.

\section{CREATION OF THE VIRTUAL NOTEBOOK}

In the fall of 2007, the digital reference graduate assistant suggested the need for a ready reference technology to support the Ask a Librarian service. Having staffed the Ask a Librarian service for a semester, she believed the methods of sharing information between staff members were ineffective. An abundance of e-mail traffic in support of librarywide reference on a local discussion list clogged in-boxes and the messages were often forgotten between shifts. Having worked as a professional librarian prior to returning to school for a $\mathrm{PhD}$, she advocated for the creation of an electronic version of the three-ring binder that she used at her previous workplaces. As a result, the Virtual Notebook was created.

Content for the Virtual Notebook was gathered from explicit knowledge distributed throughout the Libraries. One source of course was the FAQ Engine. Other sources included a local discussion list setup in support of reference at Purdue, and the archive of chat and e-mail questions from the Ask a Librarian service. The authors also created content in response to questions they had received. After content was collected it was organized organically into a small number of subject headings. The subject headings serve as the main form of navigation within the Virtual Notebook. In addition to browsing through the subject headings, users can perform keyword searches across the entire Virtual Notebook. Another feature of the Virtual Notebook is "What is Happening at the Reference Desk," an area where staff can leave messages for one another. This section was meant to replace messages shared on sticky notes at the desk or e-mails sent to the local reference discussion list.

\section{OUTCOME OF THE VIRTUAL NOTEBOOK}

The use of wiki software addressed two major challenges associated with the Reference FAQ version 2.0. First, the Virtual Notebook was easier to edit as compared to the FAQ Engine. To create or edit content within the Virtual Notebook one used the WYSIWYG (what you see is what you get) interface. In comparison, edits made to the FAQ Engine were limited and difficult due to the tool's design. The wiki also provided a revision history, making it easy to revert back to former versions of the page if needed. Second, the Virtual Notebook was built on an open architecture that all Libraries staff could edit. In contrast, staff needed special logins to create content within the FAQ Engine. Despite the benefits of being built on an open, wiki-based architecture, use of the Virtual Notebook was lower than expected as a result of a number of contributing factors.

Despite efforts to integrate these resources into the Virtual Notebook, it is in competition with other preexisting FAQs within the Libraries. If the Virtual Notebook is to be a system-wide resource, it must be comprehensive enough to accommodate the wide range of needs throughout the Libraries. FAQ content residing outside the wiki impedes its use and further development. Similarly, the Virtual Notebook faced competition from the previous intranet-a collection of webpages on a file server located behind a firewall that is still supported by the organization. Again, if the Virtual Notebook is to be fully utilized, it must become the centralized place for information to support public services.

The use of the Virtual Notebook mirrors the overall use of the intranet within the Purdue University Libraries. Early use of the intranet was encouraging, but lessened over time. Much of the use was associated with Libraries councils, commit- 
tees, and teams, but the Virtual Notebook, loosely owned by the reference services team, was created as a resource for all Libraries staff. Without overt coordination, it may have been overly optimistic to think that the resource would blossom.

Staff may be reluctant to use the intranet and consequently the Virtual Notebook because they are unfamiliar with wiki technology. Despite Libraries-wide intranet training, the authors found staff members uneasy using the intranet and the Virtual Notebook. Staff members expressed concern that information could be edited or deleted by anyone, a situation eased by the fact that wikis retain version history making it relatively easy to revert to previous versions of the page. Also, even after being described as a shared resource owned by all, staff sought permission to add content to the Virtual Notebook.

The design of the Virtual Notebook may be a factor as well. The researchers deliberately utilized an organic approach in designing the wiki. Instead of starting with an organizational model and then searching for content to fit into predetermined categories, the researchers let the categories naturally emerge from the content. It is possible that the researchers' classification schema did not match what other staff members hoped to see. Another early design decision was to focus on content acquisition over design. The early goal was not to make the Virtual Notebook look pretty, but rather to acquire a significant amount of content so that the Virtual Notebook could become a destination in and of itself.

Finally, use of the Virtual Notebook was limited because the resource resided behind a firewall, unlike the previous Reference FAQs. For staff members this should not have been a problem as they had password access to the intranet. However, the simple act of logging in to the intranet is a barrier to access. For library patrons who could not access the Virtual Notebook at all, it is a major design limitation.

\section{THE FUTURE OF THE VIRTUAL NOTEBOOK}

Utilization of the Virtual Notebook has been underwhelming thus far because of the aforementioned contributing factors. Nevertheless, the resource has potential to improve, and as a result, be used more frequently. As the Virtual Notebook is an outgrowth, or an evolution, of previous ready reference technologies, it will no doubt evolve as did earlier ready reference technologies.

Three recent developments at Purdue point to a continued and increased demand for such a tool. First, three libraries at Purdue-the Engineering Library; the Humanities, Social Science, and Education Library; and the Undergraduate Library-consolidated their reference and circulation service desks. As a result, circulation and reference staff are expected to attend to a broader array of questions than before. The next iteration of the Virtual Notebook could support changing roles of Libraries staff.

Second, in addition to service points consolidation within the Libraries, there also has been a Libraries merger into organizational units. In 2009, the Humanities, Social Science, and Education Library; the Management and Economics Library; and the Undergraduate Library joined to form the Humanities, Social Science, Education, and Business Division. Each of the three libraries operates a FAQ database separate from the Virtual Notebook. The Humanities, Social Science, and Education Library maintains a subject-specific FAQ database using the Libraries FAQ Engine. The Management and Economics Library contributes to a FAQ that is shared by college and university business libraries across the country. The Undergraduate Library has an extensive repository of FAQs from the Ask a Librarian service archive. The next iteration of the Virtual Notebook could integrate all of these disparate FAQ collections.

Third, in the near future the Libraries are expected to adopt software for collecting service desk usage statistics. Currently statistics are recorded by hand in each library on tick sheets, much in the way they were collected decades ago. The Libraries is considering using a vendor-based solution or an open-source software, or else developing a tool internally. At first glance, statistics gathering and ready reference support may appear to be separate tasks, but these functions can be integrated using the model that is common within IT help desk software. As questions come in to the library service points they would be tallied and recorded. Once recorded they could be analyzed to create new FAQs, much in the way that the Ask a Librarian service archive was utilized in creating the initial content of the Virtual Notebook. Some software allows both private and public views of the FAQ data. If the Libraries move toward an integrated system linking statistics gathering and ready reference support, this will lead to a tool that is more capable of supporting reference and user services.

\section{CONCLUSION}

Ready reference technologies must continue to evolve to meet the demands of library staff looking 
to serve library patrons in new and innovative ways. The basic tenets proposed by Eleanor Woodruff in 1897 still apply: questions will continue to "come around with the regularity of the seasons." Though we have moved away from recording answers on spoiled library cards, the process is the same, albeit with new technologies. The Virtual Notebook is one such technology built on the legacy of previous ready reference technologies. While the use of the Virtual Notebook has yet to reach the level expected by the researchers, there is no doubt that a wiki can be helpful in supporting reference and user services within a distributed library environment.

\section{References and Notes}

1. Eleanor B. Woodruff, "Reference Work," Library Journal 22 (1897): 66.

2. Ibid.

3. Robert Slater, "Reference Desk Notes: An Online Knowledge Management System," Internet Reference Services Quarterly 11, no. 3 (2006): 69-70.

4. Susan Dimattia and Norman Oder, "Knowledge Management: Hope, Hype, or Harbinger," Library Journal 122, no. 15 (Sept. 1997): 33-35; Robert Schwarzwalder, "Librarians as Knowledge Management Agents," EContent 22, no. 4 (Aug./Sept. 1999): 63-65; Robert J. Boeri and Martin Hensel, "'Special Librarians' and Enterprise Knowledge Management," EMedia Professional 11, no. 4 (Apr. 1998): 36.

5. Charles T. Townley, "Knowledge Management and Academic Libraries," College \& Research Libraries 62, no. 1 (Jan. 2001): 45.

6. Mark Stover, "Making Tacit Knowledge Explicit: The Ready Reference Database as Codified Knowledge," Reference Services Review 32, no. 2 (2004): 164-66.

7. Smiti Ghandi, "Knowledge Management and Reference Services," The Journal of Academic Librarianship 30, no. 5 (Sept. 2004): 375.

8. Steven J. Bell, "Give Your Reference Manual an Extreme E-Makeover," The Reference Librarian 48, no. 2 (2007): 73-74.

9. Diana M. Thomas, Ann T. Hinckley, and Elizabeth R. Eisenbach, The Effective Reference Librarian (New York: Academic Pr., 1981): 19-20.

10. Heather Phalen, "Supplementary Resources for Enhancing Reference Service," Ohio Library Association Bulletin 55, no. 2 (July 1985): 18.

11. Virginia Fairfax, Pamphlets and Clippings in a Business Library (San Francisco: Journal of Electricity and Western Industry, 1921): 8.

12. H.W. Wilson, "Historical Highlights from H.W. Wilson's Past," www.hwwilson.com/AboutHW/hwtime .htm (accessed May 4, 2009).

13. Norma Olin Ireland, The Pamphlet File in School, College, and Public Libraries, rev. and enld. (Boston: F.W. Faxon, 1954): 1.

14. Mark Stover and Esther Grassian, "Toward an Automated Reference Information System: Inmagic and the UCLA Ready-Reference Information Files," RQ 28, no. 4 (Summer 1989): 517-27.

15. Maureen O. Carleton and Catherine G. Cheves, "The Vertical File Enters the Electronic Age," Medical Reference Services Quarterly 8, no. 4 (Winter 1989): 1-10.
16. Randy L. Abbot, "Vertical Files Still Standing Tall," The Unabashed Librarian 72 (1989): 25.

17. Rochelle Yates, A Librarian's Guide to Telephone Reference Service (Hamden, Conn.: Library Professional Publication, 1986): 26

18. Yates, A Librarian's Guide, 28-29; Sharon McQueen and Doublas L. Zweizig, "What Goes Around Telephone Reference Rotary Wheels," Public Libraries 42, no. 5 (Sept./Oct. 2003): 309.

19. Joshua Boyer, "Virtual Reference at North Carolina State University: The First One Hundred Days," Information Technology \& Libraries 20, no. 3 (Sept. 2001): 123; Steve Coffman, Going Live: Starting \& Running a Virtual Reference Service (Chicago: ALA, 2003): 50-51; Sam Stormont, "Going Where the Users Are: Live Digital Reference," Information Technology \& Libraries 20, no. 3 (Sept. 2001): 131; M. Kathleen Kern, "Have(n't) We Been Here Before? Lessons from Telephone Reference," Reference Librarian no. 85 (2004): 6-7; Lorraine Normore and Paula Rumbaugh, "Moving From Virtual to Cooperative Reference Service Models," in Implementing Digital Reference Services: Setting Standards and Making it Real, Proceedings of the Third Annual Virtual Reference Desk (VRD) Conference, ed. R. David Lankes, Charles R. McClure, Melissa Gross, and Jeffrey Pomerantz (New York: Neal-Schuman, 2002): 106; Joseph Janes, Introduction to Reference Work in the Digital Age (New York: Neal-Schuman, 2003): 143.

20. Michael Sauers, Using the Internet as a Reference Tool (New York: Neal-Schuman, 2001): 54-55.

21. Normore, "Moving From Virtual," 107.

22. Buff Hirko and Mary Bucher Ross, Virtual Reference Training: The Complete Guide to Providing Anytime Anywhere Answers (Chicago: ALA, 2004): 13.

23. Joseph Janes, Introduction to Reference Work in the Digital Age (New York: Neal-Schuman, 2003): 144.

24. Mary C. Schlembach, "Reference Assistant: Utilizing the Web to Access Locally Generated Databases," 2000 Special Libraries Association Annual Conference, June 10-13, 2000, Philadelphia, Pa., http:// units.sla.org/division/dst/UIUC-Refassistant.html (accessed Sept. 29, 2008).

25. Slater, "Reference Desk Notes: An Online Knowledge Management System," 69-83.

26. Bell, "Give Your," 74-75.

27. Steven J. Bell, "Time to Lose the Sticky and Try a Wiki," The Reference Librarian 47, no. 2 (2007): 101-5.

28. Matthew M. Bejune, "Wikis in Libraries," Information Technology \& Libraries 26, no. 3 (Sept. 2007): 26-38.

29. Tammy Ravas, "Not Just a Policies and Procedures Manual Anymore: The University of Houston Music Library Manual Wiki," Notes 65, no. 1 (Sept. 2008): 45,47 .

30. Angela Kille, "Wiki at Work: Implementing a Wiki in Reference Services" (a poster presented at the American Library Association Annual Conference, 2006), http://angelakille.files.wordpress.com/2006/06/kille_ ala_wiki_poster.pdf (accessed Sept. 10, 2008).

31. Rob Withers, "Something Wiki This Way Comes," CERL News 66, no. 11 (Dec. 2005): 775-77.

32. Some technologies were utilized by the authors while they worked at Purdue and others were not. The authors interviewed senior staff members to learn how these technologies were previously used. 